(REVIEW ARTICLE)

\title{
Uterine rupture: risk factors and prognosis
}

\author{
Gabkika Bray Madoué 1, ${ }^{*}$, Constant Naim 2, Foumsou Lhagadang 1,2 and Damtheou Sadjoli 1,2 \\ ${ }^{1}$ N'Djamena Mother and Child hospital. \\ ${ }^{2} N^{\prime}$ Djamena Faculty of Human Health Sciences.
}

Publication history: Received on 14 November 2019; revised on 25 November 2019; accepted on 27 November 2019

Article DOI: https://doi.org/10.30574/wjarr.2019.4.2.0090

\begin{abstract}
Uterine rupture is a non-surgical breach of the continuity of the myometrial wall of the uterus. Objective: identify risk factors and evaluate the prognosis of uterine rupture. This was a descriptive and analytical study with retrospective data collection over a four-year period from January $1^{\text {st }}, 2015$ to December $31^{\text {st }}$, 2018. We recruited all cases of uterine rupture that met our criteria and matched them to the following case. The frequency of uterine rupture was $0.77 \%$. The aged group from 25-34 were most represented with $69.5 \%$. The average age was $27.1 \pm 2.3$ years with extremes of 15 and 47 years. The majority of patients (69\%) were multiparous and one hundred and forty-five patients (72.5\%) were referred. One hundred and sixty-six patients $(83 \%)$ had an unscarred uterus. Inadequate use of oxytocin was inriminated in 104 cases (52\%) with uterine rupture ( $\mathrm{p}=0.02)$. Fetopelvic disproportion was found in 32\% $(\mathrm{p}=0.002)$.The uterine rupture was complete in $76.5 \%$ of case. Suturing of uterus tear was done in $85.5 \%$. Twenty-nine patients $(14.5 \%)$ had a hysterectomy. Blood transfusion was performed in $78 \%$. Anemia was the most common complication with 67.5\% .Nineteen maternal deaths (9.5\%) were recorded. One hundred and seventy-two fetuses (86\%) were stillborn. Conclusion: This study shows that the main risk factors are a history of cesarean section, multiparity, and young age.
\end{abstract}

Keywords: Rupture Uterine; Risk Factor and Prognosis in N'djamena Mother and Child Hospital

\section{Introduction}

Uterine rupture is a non-surgical breach of the continuity of the myometrial wall of the uterus [1]. It is an obstetric disaster that threatens mother and the fetus lives. The fetal prognosis is often poor and maternal prognosis depends on the speed of diagnosis and management $[2,3]$. Chad, a developing country, is no exception to this sad reality despite the government's policy of making emergency care and deliveries free of charge over the past 10 years. In 2013, there was a hospital frequency of uterine rupture of $0.57 \%$ of deliveries [4]. Objective: given the scarcity of data on uterine rupture in Chad, the high prevalence of its risk factors and the poor maternal-fetal prognosis in African series and the lack of identification of risk factors in the local context, we were pleased to conduct this study.

\section{Patients and method}

This was a descriptive and analytical study with retrospective data collection over a four-year period from January $1^{\text {st }}$, 2015 to December 31st, 2018. Any patient admitted for uterine rupture (complete or exploitable files) during pregnancy, labor and immediate postpartum period, evacuated, referred were recorded. We recruited all cases of uterine rupture that met our criteria and matched them to the following case. Then we have a group of case constitute with patients presenting an uterine rupture, and the control group with the patient following a case of rupture. The data collected were processed using Epi data 3.1 software and the analysis was done using SPSS 20 software. p value was significant when less than 0.05 .

\footnotetext{
${ }^{*}$ Corresponding author

E-mail address: kickbray@yahoo.fr
} 


\section{Results}

\subsection{Frequency}

During the period we recorded 200 cases of uterine rupture among 25,727 deliveries giving a frequency of $0.77 \%$.

Table 1 Age

\begin{tabular}{llllll}
\hline Age & Group I & \multicolumn{3}{c}{ Group II } & p \\
& $\mathbf{n}$ & $\mathbf{\%}$ & $\mathbf{n}$ & $\mathbf{\%}$ & \\
\hline $15-24$ & 35 & 17,5 & 34 & 17 & 0,894 \\
$25-34$ & 139 & 69,5 & 140 & 70 & 0,913 \\
$35-44$ & 26 & 13 & 20 & 10 & 0,347 \\
$>45$ & 0 & 0 & 6 & 3 & 0,015 \\
Total & 200 & 100 & 200 & 100 & \\
\hline
\end{tabular}

The aged group from 25-34 were most represented with 69.5\% in Group I and 70\% in the control Group II. The average age was $27.1 \pm 2.3$ years with extremes of 15 and 47 years

Table 2 Parity

\begin{tabular}{|c|c|c|c|c|c|}
\hline \multirow[t]{2}{*}{ Parity } & \multicolumn{2}{|c|}{ Group I } & \multicolumn{2}{|c|}{ Group II } & \multirow[t]{2}{*}{$\mathbf{p}$} \\
\hline & $\mathbf{n}$ & $\%$ & $\mathbf{n}$ & $\%$ & \\
\hline primipara & 29 & 14,5 & 19 & 9,5 & 0,123 \\
\hline multiparous & 138 & 69 & 171 & 85,5 & 0,000 \\
\hline paucipara & 33 & 16,5 & 10 & 5 & 0,000 \\
\hline Total & 200 & 100 & 200 & 100 & \\
\hline
\end{tabular}

The majority of patients (69\%) were multiparous

\subsection{Admission mode}

One hundred and forty-five patients (72.5\%) were referred, compared to55 (27.5\%) who came on their own.

\subsection{State of the uterus}

One hundred and sixty-six patients (83\%) had an unscarred uterus. Thirty-two patients (16\%) had a history of cesarean section, and $1 \%$ ( 2 patients) had a history of myomectomy.

Table 3 Etiology

\begin{tabular}{llllll}
\hline \multirow{2}{*}{ Etiology } & Group I & \multicolumn{2}{c}{ Group II } & \multicolumn{2}{c}{$\mathbf{p}$} \\
\cline { 2 - 5 } & $\mathbf{n}$ & $\mathbf{\%}$ & $\mathbf{n}$ & $\mathbf{\%}$ & \\
\cline { 1 - 5 } Pelvic fetal disproportion & 64 & 32 & 93 & 46,5 & 0,0029 \\
misoprostol & 6 & 3 & 1 & 0,5 & 0,060 \\
macrosomie & 6 & 3 & 8 & 4 & 0,598 \\
Dystocic presentation & 20 & 10 & 15 & 7,5 & 0,376 \\
Inadequate use of oxytocin & 104 & 52 & 74 & 37 & 0,024 \\
\hline
\end{tabular}


Inadequate use of oxytocin was incriminated in 104 cases (52\%) of uterus rupture, compared to 74 in the control group $(\mathrm{p}=0.02)$. Fetopelvic disproportion was noted in $32 \%$ of the study group compared to $46.5 \%$ in the control group $(\mathrm{p}=0.002)$

\subsection{Type of uterine rupture}

The uterine rupture was complete for 153 patients (76.5\%). Forty-seven patients (23.5\%) had had an incomplete rupture.

Table 4 Seat of uterine rupture

\begin{tabular}{lll}
\hline Seat of uterine rupture & Number & Percentage \\
\hline isthmique & $\mathbf{1 5 0}$ & $\mathbf{7 5}$ \\
Corporeal & 4 & 2 \\
Ithmiqueqnd corporeal & 46 & 23 \\
Total & $\mathbf{2 0 0}$ & $\mathbf{1 0 0}$ \\
\hline \multicolumn{2}{r}{}
\end{tabular}

\subsection{Management}

Suturing of uterus tear was done in 171 cases (85.5\%). Twenty-nine patients (14.5\%) had a hysterectomy. Blood transfusion was performed in 156 patients (78\%).

Table 5 Maternal complication

\begin{tabular}{lll}
\hline Complication & Number & Percentage \% \\
\hline death & 19 & 09,5 \\
Parietal Suppuration & 10 & 5 \\
Endometritis & 4 & 2 \\
Vesico-vaginal fistula & 4 & 2 \\
Phlebitis & 2 & 1 \\
Anemia & 135 & 67,5 \\
Peritonitis & 2 & 1 \\
Septicaemia & 9 & 4,5 \\
\hline
\end{tabular}

Anemia was the most common complication with $67.5 \%$. Nineteen maternal deaths (9.5\%) were recorded.

\subsection{Fetal prognosis}

One hundred and seventy-two fetuses (86\%) were stillborn. Twenty-three newborns (11.5\%) had an Apgar score $\geq 7$.

\section{Discussion}

\subsection{Frequency}

The frequency of uterine rupture was $0.91 \%$. Our rate is close to $0.91 \%$ reported by Andrianampy and al in Fianarantsoa, Madagascar [5] in 2014. Our rate is lower than those of, Kouakou [6] in Bouake, Côte d'Ivoire in 2007 and Nayama in Niger[7] in 2016, which observed a frequency ranging from 2 to 2.33\%. Other authors such as Salifou in Parakou, Benin[8] in 2015, Gueye in Thiès, Senegal[9] in 2016 reported lower proportions respectively 0.58\% and $0.7 \%$.In India, the frequency of uterine ruptures is closer to African countries, $0.28 \%$ in 2006[10]. In developed 
Gabkika et al. / World Journal of Advanced Research and Reviews, 2019, 04(02), 033-038

countries, uterine rupture is an exceptional situation. This high frequency confirms that the issues of uterine rupture remains a topical one and often occur in developing world.

\subsection{Age}

Young age is found in most African series $[6,8,11]$. The median age was $27.1 \pm 2.3$ years. Which is comparable to those of Fouedjio and al [12] in Cameroon in 2016, Salifoua and al [8] in Benin in 2015, and Vangeenderhuysen [13] in Niger in 2002 , that noted respectively a median age of 29,28 and 28.9 years

In this series the age group of 25-34 years had represented 69.5\%. Our study finds a similarity in the prevalence of this age group. This is the case of Gueye in Senegal [9], Tchente Nguefack in Douala [14], Salifou in Parakou in Benin [8] which reported respectively $45 \%, 67 \%$ and $37 \%$.

\subsection{Admission method}

Patients were referred or evacuated in $72.5 \%$ of cases. Our result is similar to those of several authors including Gueye and al [9] in Thiès], and Nayama in Niamey [7] who noted that more than half of the patients were referred. This situation could be explained by the lack of qualified personnel and technical support in periphery structures leading to the referral of cases of dystocia.

\subsection{Parity}

Multiparity is known to be a risk factor for uterine rupture [8, 9, 11]. Our study confirms this assertion with $69 \%$ of multiparous women. Our data corroborate those of some authors such as Gabkika [4] in N'Djamena, Chad in 2015, Vangeenderhuysen in Niamey [13] in 2009 and Fouedjio et al in Yaounde, Camreoun [12] who noted that multiparous had represented more than half of patients

\subsection{State of the uterus}

Contrary to developed countries where uterine rupturesare often occasional, in developing countries it is a usual phenomenon $[15,16]$. Our study confirms this assertion with $83 \%$ of uterine rupture occurring on an unscarred uterus. Our result corroborates those of many authors, notably Gueye in Senegal [9], Tchente Nguefack in Douala [14], Salifou in Parakou in Benin [8], and Andrianampy in Madagascar [5], who reported a rate ranging from $61 \%$ to $88.5 \%$ of uterine rupture occurring to patients with an unscarreduterus

\subsection{Etiologies}

The etiologies of ruptures were the inadequate use of oxytocin in 52\%, followed by fetopelvic disproportions in $32 \%$. These causes are identical to those described in the literature [15, 16,17]. Iatrogenic ruptures are secondary to poor obstetric practices related to the birth attendant and the inadequate use of oxytocin.

\subsection{Type of uterine rupture}

In This series, 153 patients (76.5\%) had a complete uterine rupture. This result confirms the data from the literature $[5,7,17,18]$.

\subsection{Management}

Conservative treatment was performed in $85.5 \%$ of cases (171), and radical treatment in $14.5 \%$ of cases (29). Our results are close to those of Gabkika, who had had a conservative surgery rate of $87 \%$. Nevertheless, our radical treatment rate is lower than those of Gueye and al [9] in Senegal, Fouedjio andal [14] in Cameroon and Nayama and al [7] in Niger, which had noted a proportion of radical treatment rate ranging from 29.7 to $63.33 \%$. The decision to undergo radical treatment depends on several factors, including the complexity of the uterine rupture, associated lesions, parity and uterine atony.

\subsection{Prognosis}

We reported 19 cases of death (9.5\%), ourproportion confirms Gabkika's[16] maternel death rate of 9.3\% in the same structure in 2013. This is comparable to those of Nayama and al [7] in Niger in 2016, Salifou et al[8] in Benin in 2015, which had reported respectively a maternal death rates of $9.6 \%$ and $9.3 \%$. In developed countries, mortality is almost null $[18,19]$. 
The commonest maternal morbidity was anemia with 135 cases (67.5\%), 10 cases of parietal suppuration (5\%). Salifou and al [8] in Parakou, Benin, and Gueye andal [9] in Thiès, Senegal, reported a high a prevalence of anemia among complications.

Perinatal death was noted in $76.2 \%$ of cases in our series. This high rate noted in our series could be explained by the fact that patients were admitted with a complete uterine rupture in most cases. All cases of live births were cases of incomplete rupture and intraoperative discovery.The perinatal mortality rate in our series was $86 \%$. This high rate of perinatal death corroborates those of many African authors who reported variable proportions ranging from $66 \%$ to $93 \% .[6,7,9,17]$. Sahu [10] in India also has a high neonatal mortality rate of 94\% in his series.

\section{Conclusion}

This study shows that the main risk factors are a history of cesarean section, multiparity, and young age. The combination of factors such as the use of oxytocin, pelvic fetal disproportion and dystocic presentation are decisive for the occurrence of uterine rupture. The prognosis is poor for both mother and fetus.

\section{Compliance with ethical standards}

\section{Acknowledgments}

All authors approve the submission of this work.

\section{Disclosure of conflict of interest}

All authors have declared that there is no conflict of interest.

\section{Statement of informed consent}

For this survey we got the agreement of the N'Djamena Mother and Child hospital and ethical committee.

\section{References}

[1] Lansac J, Descamps P and Oury JC (2014). Birth practice. 8thEd Masson, 241, 344-345, 378-383.

[2] Cissé ML, Sylla MA, Gaye A, Bâ-Guèye M, Guèye M, Diouf A and Moreau JC. (2009). Uterine rupture in the Dakar suburbs (Senegal). Annals of SOGGO, 4(13), 11-5.

[3] Nayama M, Mohamed-Alzouma I, Garba M, Idi N, Oumara M, Guede S, et al (2015). Uterine obstetric ruptures at IssakaGazoby Maternity Hospital in Niamey: About a retrospective study of 195 cases over 3 years. Med. Afr. Noire, 62 (1), 49-55.

[4] Gabkika B, Foumsou L, Djongali S, Allarehene N, Kheba F, Adoum T and Adamou MA (2015) . Uterine ruptures: Epidemiological aspects and prognosis at N'djamena Mother and Child Hospital. South Sudan Medical Journal, 8, 76-79.

[5] Andrianampy HA, Rakotomahenina H, Ramamonjinirina TP, Rasolofondraibe AC, Andrianampanalinarivo HR and Solofomalala GD. (2014). Uterine rupture: indicator of non-completion of MDGs 4 and 5? Revue Tropicale deChirurgie, 8, 37-39.

[6] Kouakou P, Djanhan Y, Doumbia Y, Djanhan L and Ouattara M. (2007). Uterine ruptures: epidemiological and fetal-maternal prognosis aspects at the maternity ward of the Bouaké University Hospital (Côte d'Ivoire). CAMESSeries A Rev,05, 87-91.

[7] Nayama M, Saibou H, Garba M, Idi N, Sanou M, Sahabi S et al (2016). Management of uterine ruptures on healthy uterus at the IssakaGazoby maternity ward in Niamey. FIGO SAGO SOGOB Congress. Book of abstracts. 73.

[8] Salifou K, Bio TS, Blaise AT,Rachidi S, Justin D, Antoine L and René-Xavier P. (2015). Uterine ruptures at the Parakou referral hospital in Benin: epidemiological, therapeutic and prognostic aspects. European Scientific Journal, 11(24), 149-160.

[9] Gueye L, Thiam M, Niang MM, Sarr FR, Ba PA, Mahamat S et al (2016). Uterine ruptures at the Regional Hospital of Thiès (Senegal). OAS Journal, 16(2), 28- 32. 
[10] Sahu L. (2006). A 10 year analysis of uterine rupture at a teaching hospital. J ObstetGynecol India, 56(60), 502506.

[11] Sepou A, Yanza MC, Nguembi E, Ngbalé R, Kouriah G, Kouabosso A et al (2002). Uterine ruptures in the maternity ward of the Banhui Community Hospital (CAR). Méd Trop, 62 (5), 517-20.

[12] Fouedjio JH, Ngo DM, Fouelifack YF, Fouogue T. Uterine ruptures in two university hospitals in the city of Yaoundé: Clinical and therapeutic aspects. Health Sci Dis, 17(3), 34-40.

[13] Vangeenderhuysen C and Souidi A. (2016). Uterine ruptures on pregnant uterus. Study of 63 cases at the reference maternity unit in Niamey (Niger). Med. Trop, 62(6), 615-618.

[14] TchenteNguefack. (2016). uterine rupture at Douala General Hospital: Prevalence, associated factors, management and prognosis. Health Sci. Say, (17), 1-6.

[15] Merger R, Levy J and Melchior J. (2000). Précis d'obstétrique Ed Masson, Paris. 304-309.

[16] Anate P, Séror J, Afak N andLuton D. (2014). Uterine rupture during pregnancy. EMC Ed Masson, Paris. Obstetrics, 5-080-A-10

[17] Rajaonarison JJC, Fenomanana MS and Randriambelomanana JA. (2014). Uterine rupture during labour: etiological factors and maternal-fetal prognosis at the University Hospital of Obstetrical Gynecology of Befelatanana Antananarivo Madagascar. Rev. Anesthesia-reanimation. Med. Emergency, 6(1), 8-12.

[18] Zwart JJ, richters J M and Ory F. (2009). Uterine rupture in The Netherlands: a nationwide population-based cohort study. BJOG, 116, 1,069-1,078.

[19] Guiliano M, Closset E, Therby D, LeGoueff F, Deruelle P and Subtil D (2014). Signs, symptoms and complications of complete and partial uterine ruptures during pregnancy and delivery. Eur J ObstetGynecolReprodBiol, 179, $130-4$.

\section{How to cite this article}

Gabkika BM,Constant N, Foumsou L and Damtheou S. (2019). Uterine rupture: risk factors and prognosis. World Journal of Advanced Research and Reviews, 4(2), 33-38. 